\title{
The association between Helicobacter pylori and obesity: a systematic review and meta-analysis of case-control studies
}

\author{
Ali Baradaran', Hojat Dehghanbanadaki², Sara Naderpour ${ }^{3}$, Leila Mohammadi Pirkashani ${ }^{4}$, Abdolhalim Rajabi ${ }^{5}$, \\ Roya Rashti ${ }^{6}$, Sevda Riahifar ${ }^{7}$ and Yousef Moradi ${ }^{6 *}$ (D)
}

\begin{abstract}
Introduction: The relationship between H. pylori infection and obesity development has remained controversial among various studies. The aim of this study was to clarify the pooled effect of $\mathrm{H}$. pylori infection on the development of obesity and vice versa.

Methods: We searched international databases including Medline (PubMed), Web of sciences, Scopus, EMBASE, Cochrane, Ovid, and CINHAL to retrieve all case-control studies reporting the effect of $\mathrm{H}$. pylori on obesity and vice versa, which had been published in English between January 1990 and June 2019. The quality of included studies was assessed by the Modified Newcastle-Ottawa Scale for Case-Control studies. The logarithm of the odds ratio (OR) and its standard error was used for the meta-analysis.

Results: Eight case-control studies with 25,519 participants were included for qualitative and quantitative analyses. The pooled analysis showed that obese participants had a higher risk of $\mathrm{H}$. pylori infection than lean participants with an odds ratio of $1.46(95 \% \mathrm{Cl}: 1.26,1.68)$. Also, the pooled analysis revealed that participants infected by H. pylori had a higher risk of obesity than non-infected participants with an odds ratio of 1.01 (95\%Cl: 1.01, 1.02).

Conclusion: The results of this meta-analysis showed that there was a positive correlation between the risk of $\mathrm{H}$. pylori infection and the prevalence of obesity development. Thus, $\mathrm{H}$. pylori positive patients were more likely to be obese, and obese individuals had higher risks of H. pylori infection.
\end{abstract}

Keywords: Helicobacter pylori, Obesity, Case-control, Systematic review, Meta-analysis

\section{Introduction}

Obesity as a chronic non-communicable disease has become a significant public health concern around the world, which can result in or exacerbate a high burden of health conditions like hypertension, hyperlipidemia, cardiovascular diseases, diabetes mellitus, chronic kidney diseases, fatty liver diseases, etc. Besides, its prevalence

\footnotetext{
*Correspondence: Yousefmoradi211@yahoo.com

${ }^{6}$ Social Determinants of Health Research Center, Research Institute for Health Development, Kurdistan University of Medical Sciences, Sanandaj 66179-13446, Iran

Full list of author information is available at the end of the article
}

has increased during recent years, probably due to modern lifestyles, less physical activity, high-calorie intake, and so on [1-4]. Recently, animal and human studies revealed that gut microbiota could balance the energy hemostasis of the host and subsequently influence the development of obesity $[5,6]$. In a retrospective study on the Chinese population, the results showed that the prevalence of Helicobacter pylori infection in obese people was higher than that in non-obese people, but the results were not statistically significant [7]. In a meta-analysis of the Chinese population, the results showed that people with Helicobacter pylori infection had an odds ratio of original author(s) and the source, provide a link to the Creative Commons licence, and indicate if changes were made. The images or other third party material in this article are included in the article's Creative Commons licence, unless indicated otherwise in a credit line to the material. If material is not included in the article's Creative Commons licence and your intended use is not permitted by statutory regulation or exceeds the permitted use, you will need to obtain permission directly from the copyright holder. To view a copy of this licence, visit http://creativecommons.org/licenses/by/4.0/. The Creative Commons Public Domain Dedication waiver (http://creativeco mmons.org/publicdomain/zero/1.0/) applies to the data made available in this article, unless otherwise stated in a credit line to the data. 
1.20 times higher than those without infection [8]. Also, a meta-analysis study conducted to determine the exact prevalence of Helicobacter pylori infection, showed that the prevalence of this infection in the world was $44.3 \%$, which was higher in men than women [9].

In this subject, the correlation between obesity and $\mathrm{Hel}$ icobacter pylori $(\mathrm{H}$. pylori) has been evaluated in many studies [10-12]. H. pylori is a spiral-shaped, non-sporeforming and gram-negative bacterium residing on the epithelium of the human stomach. It has been reported that 4.4 billion people around the world were infected with this pathogen in 2015, who approximately included the half of the world [9]. This kind of bacteria affects human health through developing various diseases, e.g. peptic ulcer diseases, gastric cancer, and mucosa-associated lymphoma [13-15]. However, the relationship between $\mathrm{H}$. pylori infection and obesity development has been controversial between various studies [10-12, $16,17]$. So far, various studies have been done, both as a case study and as a cohort, to investigate the relationship between the presence of Helicobacter pylori infection and the occurrence of obesity or vice versa, but contradictory results of these studies have been published. Some studies showed that people with Helicobacter pylori infection had a higher body mass index than people without infection. An Israeli study found that people with Helicobacter pylori infection were more obese than healthy people while another study found no link between infection and the occurrence of obesity [18]. Lender $\mathrm{N}$ et al. also found in a review study that there was no association between obesity and the prevalence of Helicobacter pylori infection. In a study on 3,578 people aged 16 to 64 years, the results showed that the presence of Helicobacter pylori infection increased the metabolic syndrome incidence in patients so that the risk was higher in women than men $[14,19,20]$. According to the statements above, no meta-analysis study has been performed in the world to determine the association between Helicobacter pylori infection and obesity or vice versa. Conducting such a study, in addition to achieving the appropriate effect size to find a causal relationship, can provide suitable information to health policy makers and clinicians to take appropriate preventive measures and timely treatment. Therefore, the current meta-analysis aimed to clarify the pooled effect of $\mathrm{H}$. pylori infection on the development of obesity and vice versa.

\section{Methods}

This systematic review and meta-analysis were in accordance with the guidelines of Preferred Reporting Items for Systematic Reviews and Meta-Analyses (PRISMA) for reviews of analytical observational studies (case-control) [21-23].

\section{Search strategy and screening}

We searched Medline (PubMed), Web of sciences, Scopus, EMBASE, Cochrane, Ovid, and CINHAL for original articles published in English from January 1990 to December 2019. We used the following index terms and keywords: "Helicobacter pylori", "Campylobacter pylori", "Obesity", "Hypoventilation Syndrome", "Obesity-Hypoventilation Syndrome", "Abdominal Obesities", "Central Obesity", "Visceral Obesity", "Benign Obesity Metabolically Healthy Obesity", "Metabolically Benign Obesity", "Healthy Obesity", "Severe Obesities", "Morbid Obesity", "Body Mass Index", "Overweight", and "Quetelets Index". After removing duplicated articles from the primary search results, two independent reviewers (SN and $\mathrm{AB}$ ) screened the title and abstract of the remaining articles and eliminated the irrelevant ones. Any disagreement between them was discussed and if no consensus was achieved, the conflict was resolved by the third researcher (YM). The PRISMA flowchart of this study was shown in Fig. 1.

\section{Eligibility criteria}

The articles met the following criteria, were included in this systematic review: (1) case-control studies, (2) human populations, (3) study populations were patients with $\mathrm{BMI} \geq 25$, and (4) Helicobacter pylori infection was an independent variable. Besides, the exclusion criteria were case reports, reviews, animal studies, letters to the editor, and cohort studies.

\section{Data extraction}

A data extraction form was created based on our group discussion according to 10 different types of the study. Then, it was modified and used by the data extractors. Two researchers (AB and $\mathrm{SN}$ ) independently extracted and entered data into the modified extraction form. Any disagreement was assessed by both and if a consensus was not reached, a third researcher (YM) would make a decision. The following information was extracted from the included studies: 1) the name of the first author, 2) the date of publication, 3) the country, 4) control subjects, 5) study populations, 6) the age, 7) the mean of BMI, 8) measurement of association, 11) controlled variables, and 12) the method of bacteria detection.

\section{Quality assessment or risk of bias}

All studies were assessed by the Modified NewcastleOttawa Scale for case-control studies [24]. Using this tool, each study was judged in terms of eight items, and categorized into three groups: the selection of the study groups; the comparability of the groups; and how to measure exposure and the desired outcome in 


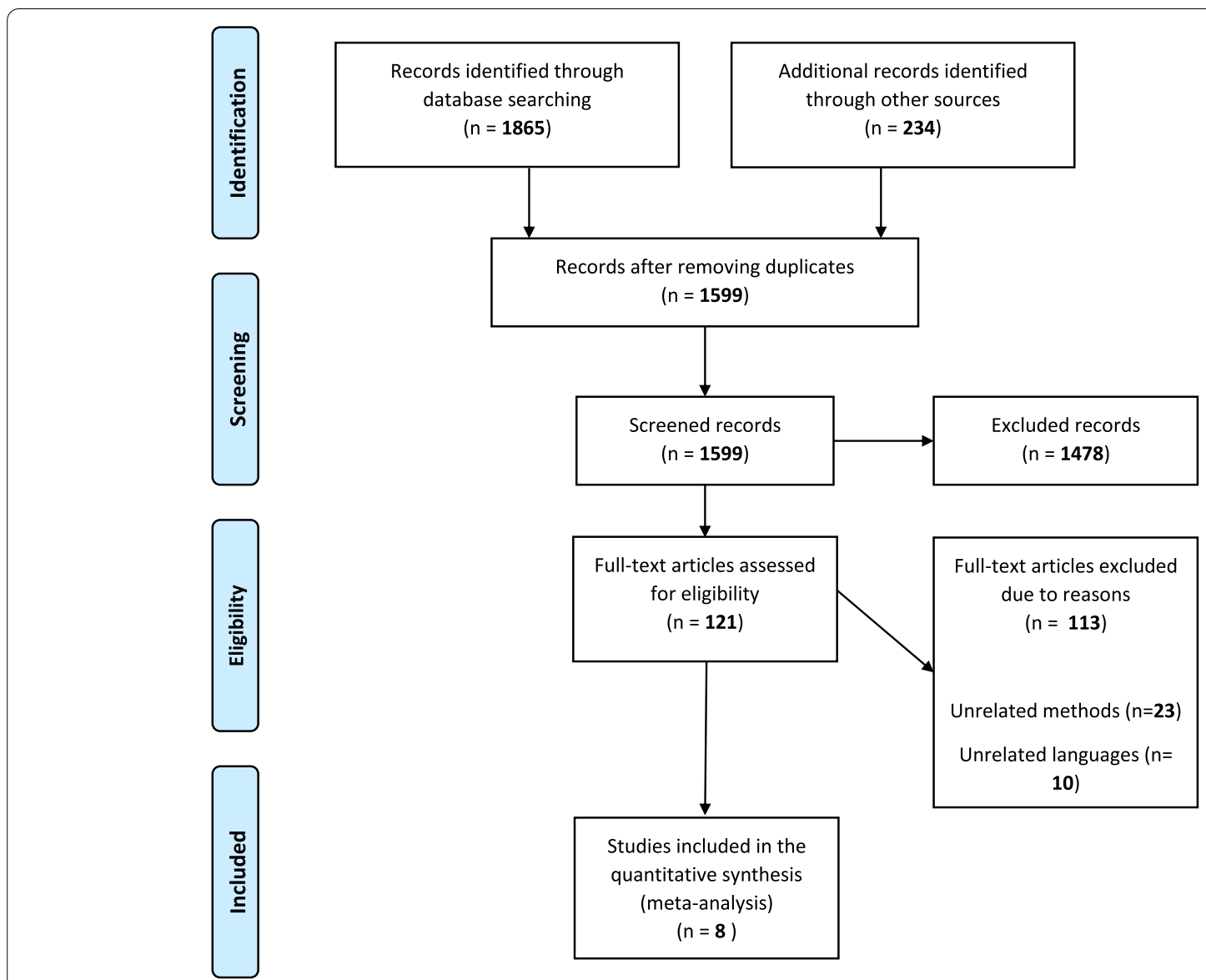

Fig. 1 The flow diagram of the literature search and study selection

the selected case-control studies [25]. Two researchers ( $\mathrm{YM}$ and $\mathrm{AB}$ ) independently evaluated the quality of included studies and the results were reported in Table 1.

\section{Statistical analysis}

The logarithm and standard error logarithm odds ratio (OR) were used for the meta-analysis. The DerSimonian and Laird method was used to compute the pooled estimate of odds ratio (OR) with a $95 \%$ confidence interval $(95 \% \mathrm{CI})[12]$. Because the test for heterogeneity was statistically significant in some analyses, the random effect models were used to estimate the OR. In this study, the w Cochran's Q test and $\mathrm{I}^{2}$ statistic were used to evaluate statistical heterogeneity between studies [13]. Besides, a meta-regression and subgroup analysis were performed to assess the source of heterogeneity between studies. Moreover, publication bias was assessed by the funnel plot and Egger and Begg's test $[14,15]$. Statistical analysis was performed using STATA 16.0 (Stata Corp, College Station, TX, USA).

\section{Results}

Study selection and characteristics

Our search strategy yielded a total of 1599 possibly relevant articles after the removal of the duplicate ones. Through screening the title and abstract of the retrieved articles, 1478 ones were excluded due to irrelevancy and the remaining 121 articles were reviewed in the full-text for eligibility assessment. Finally, 8 case-control studies $[11,12,26-31]$ were selected for meta-analysis by passing the inclusion and exclusion criteria filters (Fig. 1). The general characteristics of the included studies were demonstrated in Table 1. In total, 25,519 participants aged between 24 and 46 years, were included in our metaanalysis. Four studies with 22,830 participants evaluated the impact of obesity on the risk of $\mathrm{H}$. pylori infection while the other four studies with 2689 participants evaluated the effect of $\mathrm{H}$. pylori on the development of obesity. These studies were carried out in different geographical populations consisted of Saudi Arabia, Mexico, Taiwan, Turkey, China, Pakistan, and the USA, between 2004 and 2018. In addition, various techniques were employed to detect the $\mathrm{H}$. pylori infection, including the histology or 


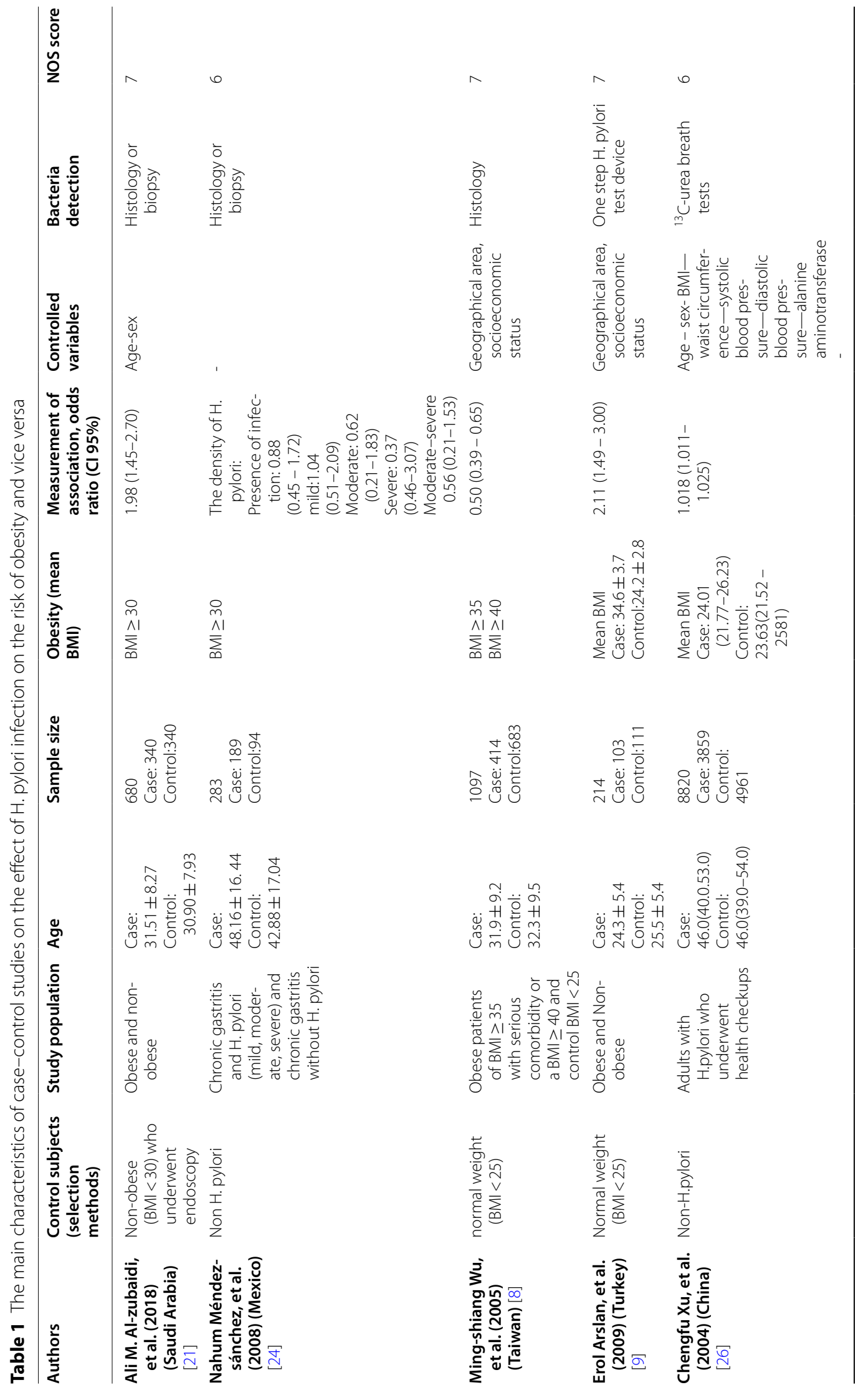




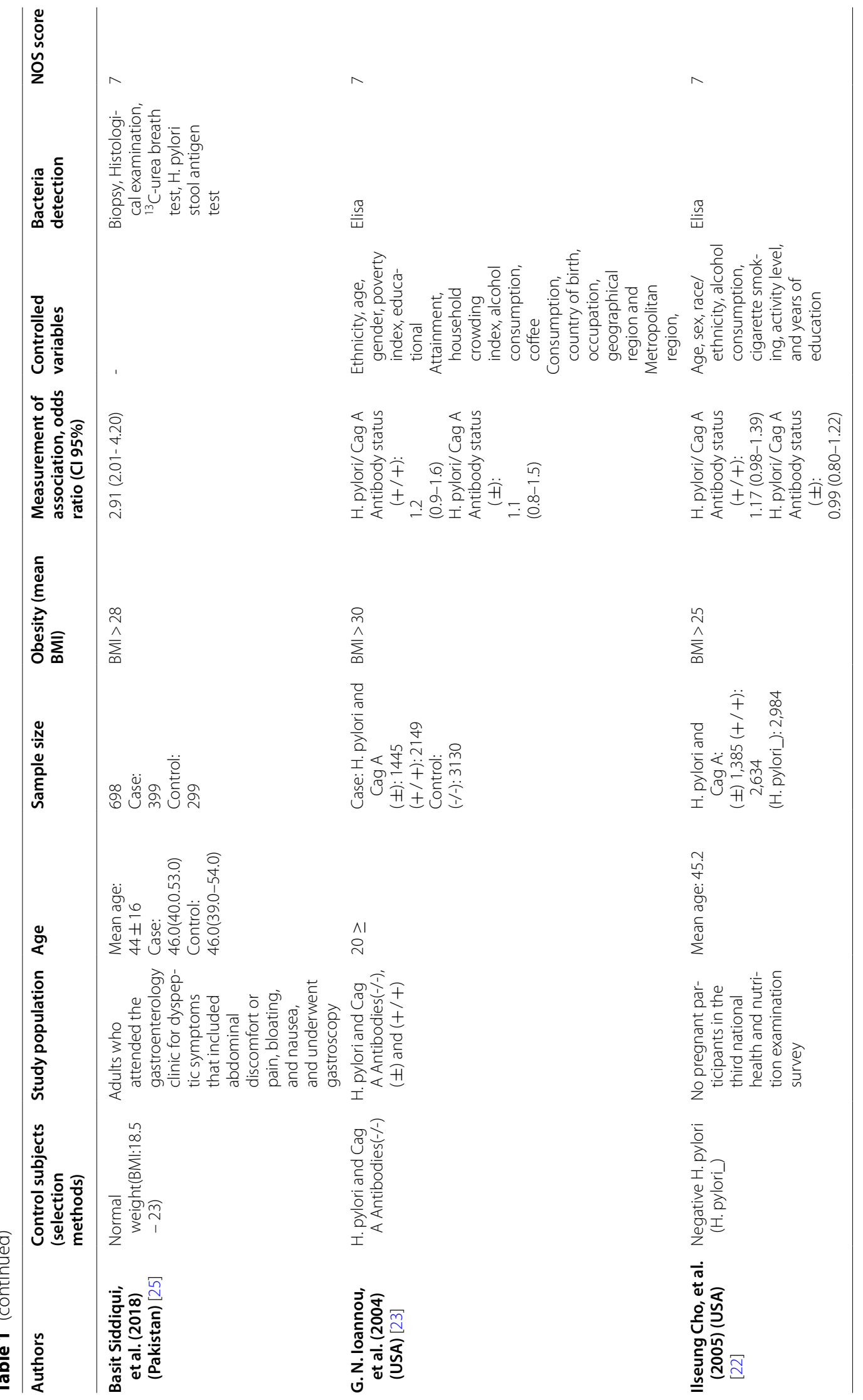


biopsy ( $n=4$ studies), ${ }^{13} \mathrm{C}$-urea breath test ( $n=2$ studies), ELISA ( $n=2$ studies), H. pylori stool antigen test $(n=1$ study), and one step H. pylori test device ( $n=1$ study).

\section{The effect of obesity on the development of $\mathrm{H}$. pylori}

The odds ratio of studies evaluating the effect of obesity on the risk of $\mathrm{H}$. pylori infection ranged between 0.50 (95\% CI: 0.39, 0.65) and 2.91 (95\% CI: 2.01, 4.21); the pooled analysis of these studies revealed that the risk of $\mathrm{H}$. pylori infection was higher in obese participants than that in lean participants with an odds ratio of 1.56 (95\% CI: $1.09,3.65)$ and there was low heterogeneity between these studies in estimating the effect of obesity on the risk of $\mathrm{H}$. pylori infection (I-squared $=58.03 \%, p=0.04$ ) (Fig. 2).

\section{The effect of $\mathrm{H}$. pylori on the development of obesity}

The results showed that if the status of both $\mathrm{H}$. pylori and Cag A Antibody were positive, there was a significant relationship between the presence of $\mathrm{H}$. pylori infection and the occurrence of obesity (OR:1.18; 95\% CI: 1.00, 1.35) (Fig. 3). However, in the presence of the positive status of $\mathrm{H}$. pylori and the negative status of Cag A Antibody, the effect of $\mathrm{H}$. pylori infection on the occurrence of obesity was 1.02 (95\% CI: $0.84,1.20)$, which was not statistically significant (Fig. 3).

\section{Subgroup analysis of the pooled effect of H. pylori infection on obesity}

The subgroup analysis based on the method of diagnosis, would be demonstrated if ELIZA was employed to detect the $\mathrm{H}$. pylori infection. The pooled odds ratio of $\mathrm{H}$. pylori infection on the risk of obesity development was 1.11 (95\% CI: 0.99 - 1.25) while the odds ratios of the histology/biopsy technique and ${ }^{13} \mathrm{C}$-urea breath test were 0.88 (95\% CI: 0.45 - 1.72) and 1.01 (95\% CI: $1.00-1.02$ ), respectively. By the way, four studies utilized ELIZA to detect $\mathrm{H}$. pylori infection among the participants and there was no heterogeneity between the results of these studies (I-squared $=0.0 \%, p=0.627$ ) (Table 2).

\section{Subgroup analysis of the pooled effect of obesity on $\mathrm{H}$. pylori infection}

On the other hand, the subgroup analysis of the pooled effect of obesity on the risk of $\mathrm{H}$. pylori infection based on the method of diagnosis, revealed that in three studies that had utilized the histology/biopsy approach, obesity didn't significantly increase the odds of $\mathrm{H}$. pylori infection (odds ratio $=1.14 ; 95 \% \mathrm{CI}: 0.96-1.36$ ) while in other diagnostic methods, e.g. the ${ }^{13} \mathrm{C}$-urea breath test and one step H. pylori test device, obesity increased the odds of $\mathrm{H}$. pylori infection with an odds ratios of 2.11 (95\% CI: $1.48-2.99$ ) and 2.91 (95\% CI: $2.01-4.20)$, respectively. However, it is noteworthy that there was low heterogeneity between studies estimating the effect of obesity on $\mathrm{H}$. pylori infection through the histology/biopsy approach (I-squared $=60.0 \%, p=0.145)$ (Table 2 ).

\section{Publication bias}

Because zero was not in the $95 \%$ confidence interval of the Egger's test, significant bias occurred in the publication of the results related to the effect of obesity on the risk of H. pylori infection (Egger's test $=4.10, P=0.003$, 95\% CI: 2.68 to 5.52). The funnel plot of the pooled effect of obesity on the risk of $\mathrm{H}$. pylori infection was shown in Fig. 4(A). Also no significant bias occurred

\begin{tabular}{|c|c|c|c|c|c|}
\hline \multicolumn{2}{|l|}{ Study } & & & $\begin{array}{c}\text { OR } \\
\text { with } 95 \% \mathrm{CI}\end{array}$ & $\begin{array}{c}\text { Weight } \\
(\%)\end{array}$ \\
\hline Al-Zubaidi, Ali. et al, 2018 & & & & $1.98[1.45,2.70]$ & 25.07 \\
\hline Ming-Shiang, Wu. et al, 2005 & & & & $0.50[0.39,0.65]$ & 25.35 \\
\hline Arslan, Erol. et al, 2009 & & & & $2.11[1.49,2.99]$ & 24.85 \\
\hline Siddiqui, Basit. et al, 2018 & & & & $2.91[2.01,4.21]$ & 24.73 \\
\hline \multirow{2}{*}{\multicolumn{6}{|c|}{$\begin{array}{l}\text { Overall } \\
\text { Heterogeneity: } \tau^{2}=0.13, \mathrm{I}^{2}=58.03 \%, \mathrm{H}^{2}=3.84\end{array}$}} \\
\hline & & & & & \\
\hline \multicolumn{6}{|c|}{ Test of $\theta_{\mathrm{i}}=\theta_{\mathrm{j}}: \mathrm{Q}(3)=6.52, \mathrm{p}=0.04$} \\
\hline \multicolumn{6}{|l|}{ Test of $\theta=0: \mathrm{z}=1.03, \mathrm{p}=0.30$} \\
\hline & $1 / 2$ & 1 & 2 & 4 & \\
\hline
\end{tabular}




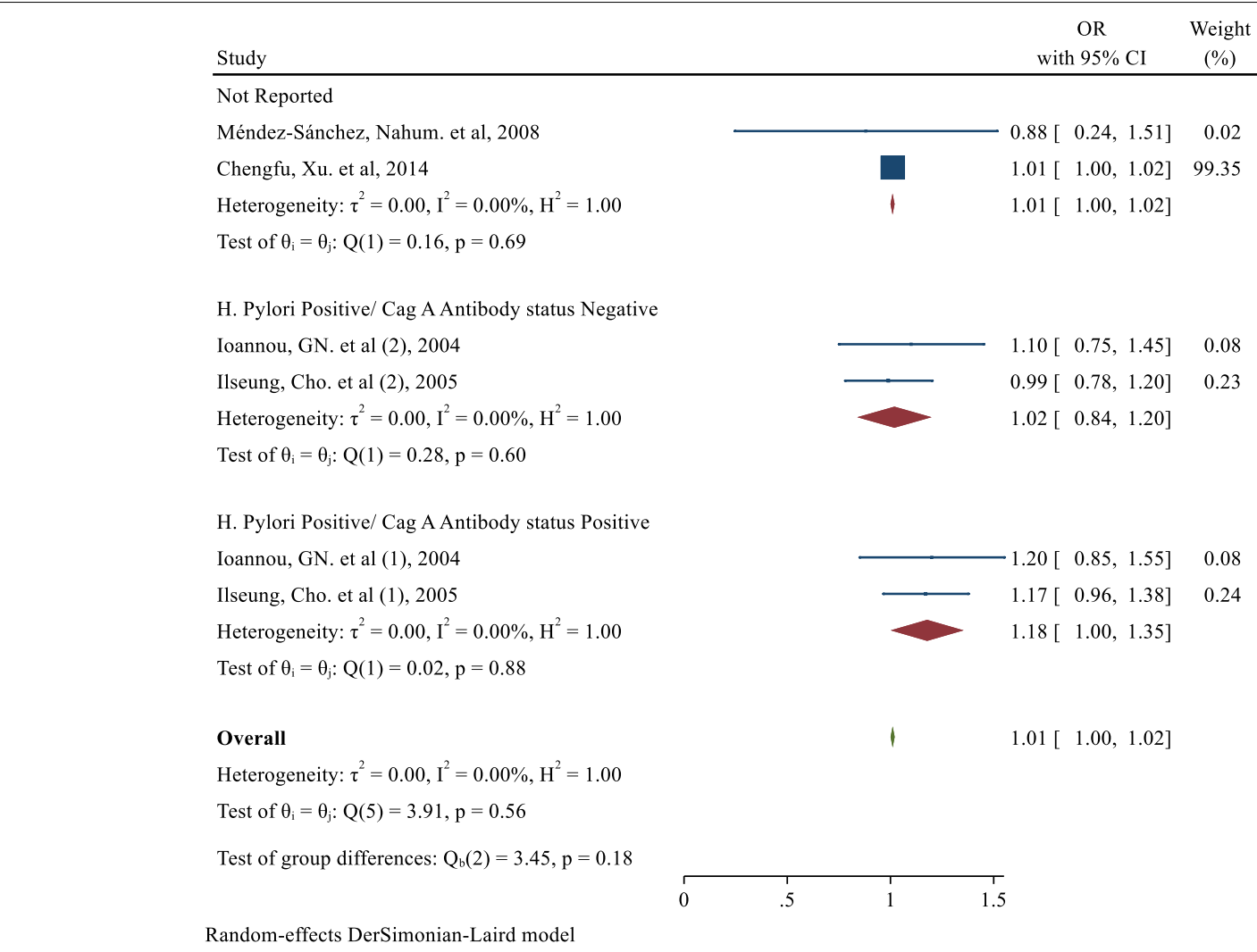

Random-effects DerSimonian-Laird model

Fig. 3 The effect of Helicobacter pylori infection on the risk of obesity

Table 2 Subgroup analysis of the pooled effect of obesity on H. pylori infection and vice versa based on the diagnosis method

\begin{tabular}{|c|c|c|c|c|c|c|c|c|}
\hline \multirow[t]{2}{*}{ Effect } & \multirow[t]{2}{*}{ Subgroup } & \multirow{2}{*}{$\begin{array}{l}\text { No. of } \\
\text { studies }\end{array}$} & \multirow{2}{*}{$\begin{array}{l}\text { Summary odds } \\
\text { ratio }(95 \% \mathrm{Cl})\end{array}$} & \multicolumn{3}{|c|}{ Between studies } & \multicolumn{2}{|c|}{ Between subgroups } \\
\hline & & & & $\mathrm{I}^{2}$ & $P_{\text {heterogeneity }}$ & $Q$ & $\bar{Q}$ & $P_{\text {heterogeneity }}$ \\
\hline \multirow[t]{7}{*}{ H. pylori on obesity } & Variables adjusted & & & & & & & \\
\hline & Yes & 5 & $1.01(1.01-1.03)$ & $6.6 \%$ & 0.372 & 4.03 & 4.03 & 0.0001 \\
\hline & No & 1 & $0.88(0.45-1.72)$ & - & - & - & & \\
\hline & Method of diagnosis & & & & & & & \\
\hline & ELIZA & 4 & $1.11(0.99-1.25)$ & $0.0 \%$ & 0.627 & 1.76 & 4.03 & 0.006 \\
\hline & Histology and biopsy & 1 & $0.88(0.45-1.72)$ & - & - & - & & \\
\hline & ${ }^{13} \mathrm{C}$-urea breath test & 1 & $1.01(1.00-1.02)$ & $0.0 \%$ & 0.515 & 1.43 & & \\
\hline \multirow[t]{4}{*}{ Obesity on H. pylori } & Method of diagnosis & & & & & & & \\
\hline & Histology and biopsy & 3 & $1.14(0.96-1.36)$ & $40.0 \%$ & 0.180 & 1.55 & 5.14 & 0.001 \\
\hline & ${ }^{13} \mathrm{C}$-urea breath test & 1 & $2.11(1.48-2.99)$ & - & - & - & & \\
\hline & One step H. pylori test device & 1 & $2.91(2.01-4.20)$ & - & - & - & & \\
\hline
\end{tabular}

in the publication of the results of the $\mathrm{H}$. pylori effect on the development of obesity (Egger's test $=0.437$, $P=0.265$, 95\% CI: -0.50 to 1.37 ). The funnel plot of the pooled effect of $\mathrm{H}$. pylori on the development of obesity was shown in Fig. 4(B).

\section{Discussion}

This study was the first meta-analysis investigating the correlation between $\mathrm{H}$. pylori infection and obesity worldwide. The pooled analysis of 8 case-control studies demonstrated that the $\mathrm{H}$. pylori prevalence in 
A

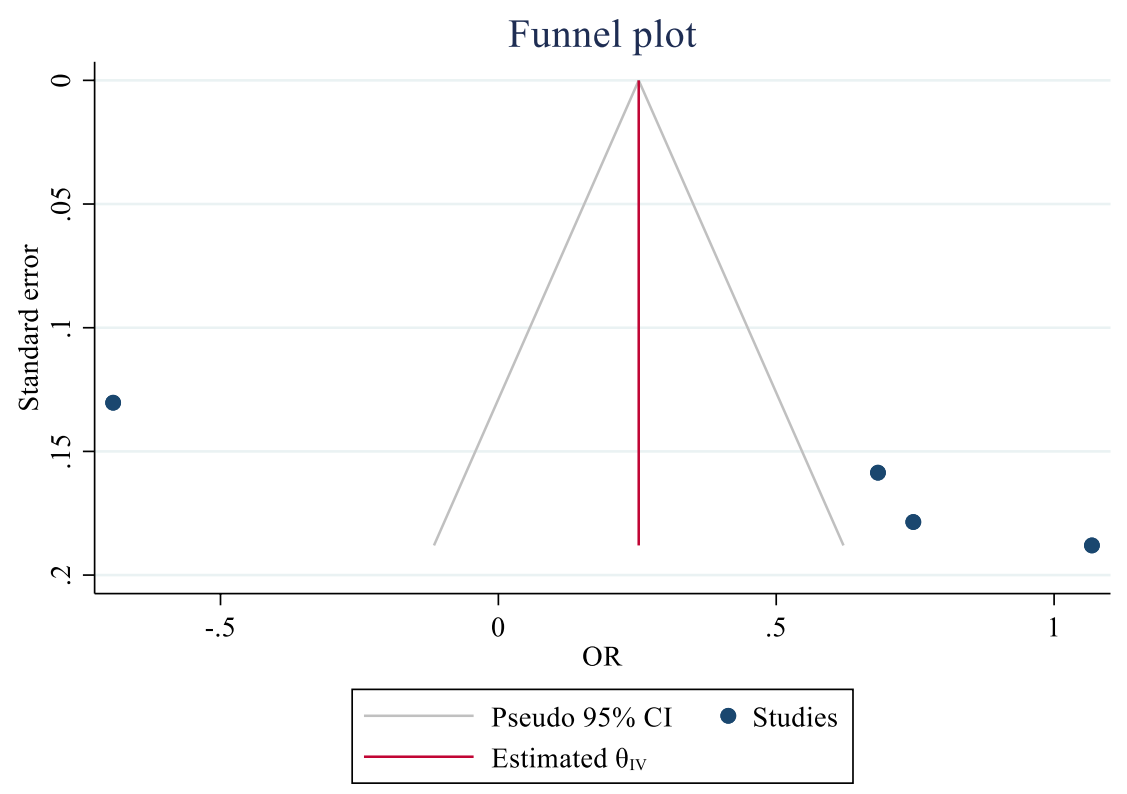

B

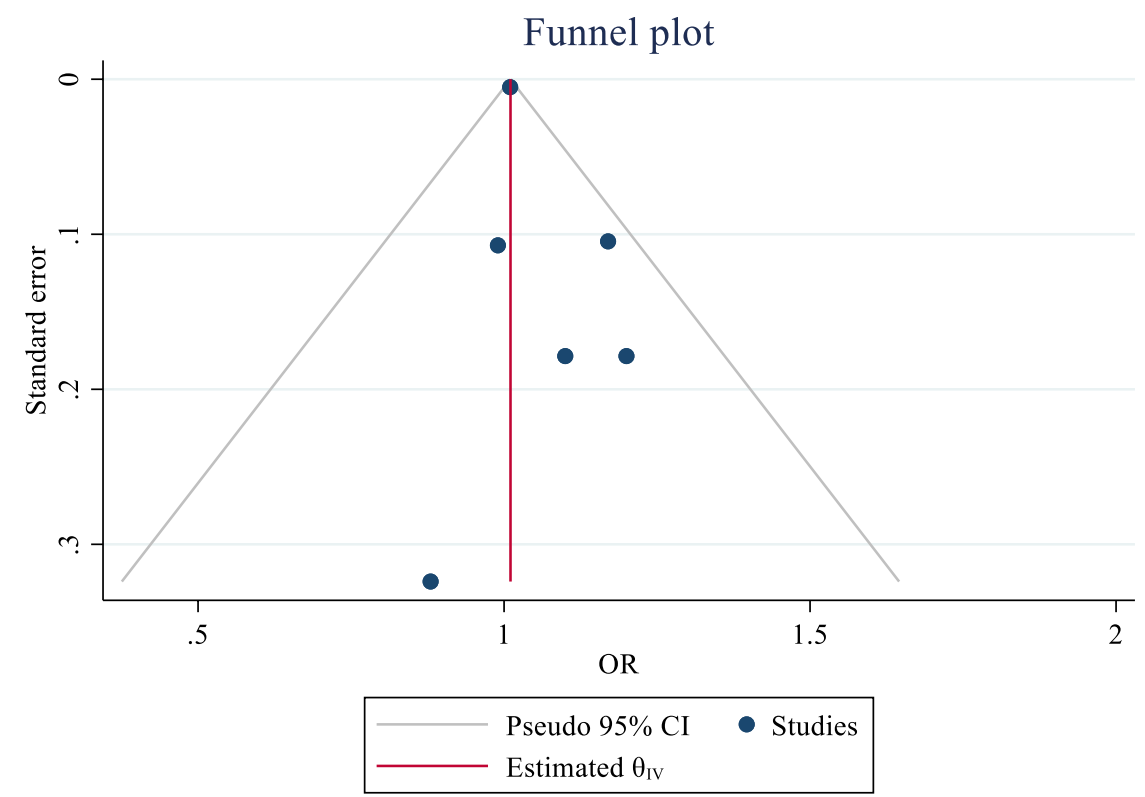

Fig. 4 The funnel plot of the obesity effect on the risk of Helicobacter pylori infection (A) and the effect of Helicobacter pylori on obesity (B)

the obese population was higher than that in the normal population and also, $\mathrm{H}$. pylori positive individuals were more likely to be obese than $\mathrm{H}$. pylori negative individuals. Therefore, there was a positive correlation between the prevalence of obesity and the risk of $\mathrm{H}$. pylori infection around the world.
The underlying mechanisms of these results are not well-recognized; however, some potential pathways explain these findings. First, regulation of the gastric hormones (e.g. ghrelin and leptin) deals with the energy hemostasis [32]. The ghrelin secretion by P/D1 cells of stomach in hunger status increases appetite and induces 
food intake while the leptin secretion by P cells of stomach and adipocytes following food intake, decreases appetite and induces satiety [33, 34]. H. pylori positive individuals have lower plasma levels of ghrelin and leptin than non-infected individuals. Therefore, lower serum leptin delays the feeling of satiety during eating and leads to more energy intake and develops obesity. Meanwhile, the lower serum ghrelin in $\mathrm{H}$. pylori-infected patients indicates lower production of this hormone due to atrophic gastritis as well as the physiological response of the body to positive energy balance in the obese population [35-37]. In addition, it is revealed that the cure of $\mathrm{H}$. pylori infection increases the serum ghrelin level [38]. The second potential factor that explains the positive relationship between the risk of obesity and $\mathrm{H}$. pylori infection is the higher insulin resistance in $\mathrm{H}$. pylori positive patients, that leads to obesity development [39]. The third factor that potentially interferes with our findings, is the impairment of the immune function of the gastrointestinal tract among the obese population. Accordingly, the monocytes of the immune system have a low ability of maturation into macrophages [40-42] and also, the natural killer cells of obese individuals have less cytotoxic activity than those of healthy-BMI individuals, that both result in less bactericidal activity, higher susceptibility of $\mathrm{H}$. pylori survival and the higher prevalence of $\mathrm{H}$. pylori infection in obese subjects [43].

The meta-analysis by Xu et al. [44] in 2019 revealed that $H$. pylori infection increased the risk of obesity development among the Chinese population with an odds ratio of 1.20 (95\% CI: 1.13 to 1.28). This relationship was congruent with our findings. It has been also reported that $\mathrm{H}$. pylori positive patients had higher total cholesterol, triglyceride, and LDL levels and a lower HDL level [44].

In this meta-analysis, the results showed that the effect of Helicobacter pylori infection on the occurrence of obesity after a combination of studies controlling confounding variables was 1.01 with a confidence interval of 1.01 to 1.03 . It could be argued that there was almost no association between the presence of infection and the occurrence of obesity because the size of the association was not very significant. Based on the diagnosis method of Helicobacter pylori infection, the results showed that, after combining the results of studies which had used the ELIZA method to detect bacteria, the effect size was 1.11 with a confidence interval of 0.99 to 1.25 , indicating that people with infection were $11 \%$ more obese than people who did not have an infection. This relationship was close to a significant level. In this subgroup analysis, the heterogeneity rate in all was close to $0 \%$, which indicated the absence of heterogeneity in these analyzes and studies. In determining the relationship between obesity and the incidence of Helicobacter pylori infection, after combining the results of case studies that diagnosed the infection using the histology and biopsy, the odds ratio was 1.14 , but was not statistically significant and the amount of heterogeneity decreased relative to the overall findings. This indicated that different diagnostic methods to determine the association between obesity and infection were a major source of heterogeneity and its creation in the overall combination of studies.

\section{Limitations}

One of the limitations of this study was the limited number of articles that did not allow the investigation of the relationship based on important variables. In addition, the most important limitation of this study was the lack of isolation of Helicobacter pylori genotypes in metaanalysis studies. Also, the type of Helicobacter pylori strains was not specified in the studies. For example, Helicobacter pylori type I is more involved in the occurrence of metabolic disorders than the type II. If these cases were identified, the authors could perform subgroup analysis in this study based on these variables and could compare the effects. Obesity is also a disorder that is strongly influenced by the lifestyle and genetic or hereditary factors. It is suitable to conduct a more detailed study in the future in the form of cohort studies with an appropriate sample size in order to determine this effect by precisely controlling the confounding variables.

\section{Conclusion}

The prevalence of $\mathrm{H}$. pylori infection in obese individuals was higher than that in the healthy-BMI population and also the risk of obesity development in $\mathrm{H}$. pyloripositive patients was higher than that in non-infected participants.

\section{Acknowledgements}

No.

\section{Disclosure statement}

No potential conflict of interest was reported by the authors.

\section{Authors' contributions}

Conceptualization: Yousef M and Ali B. Data curation: Yousef M, Sara N, and Ali B. Formal analysis: Yousef M. Funding acquisition: Hojat D, Ali B, Abdolhalim R, and Leila MP. Methodology: Yousef M, and Abdolhalim R. Project administration: Yousef M. Software: Yousef M, and Ali B. Supervision: Yousef M. Validation: Yousef M. Writing - original draft: Hojat D, Sara N, Abdolhalim R, SR and Leila MP. Writing - review \& editing: Yousef M, and Ali B. The author(s) read and approved the final manuscript.

\section{Funding}

Not applicable.

Availability of data and materials

All relevant data are within the manuscript and its supporting information files. 


\section{Declarations}

Ethics approval and consent to participate Not applicable.

\section{Consent for publication}

Not applicable.

\section{Competing interests}

The authors declare that they have no competing interests.

\section{Author details}

${ }^{1}$ Endocrine Research Center, Institute of Endocrinology and Metabolism, Iran University of Medical Sciences, Tehran, Iran. ${ }^{2}$ Students Scientific Research Center, Tehran University of Medical Sciences, Tehran, Iran. ${ }^{3}$ Department of Epidemiology, School of Public Health, Iran University of Medical Sciences, Tehran, Iran. ${ }^{4}$ Clinical Research Development Center, Imam Reza Hospital, Kermanshah University of Medical Sciences, Kermanshah, Iran. ${ }^{5}$ Department of Health Management and Social Development Research Center, Faculty of Health, Golestan University of Medical Sciences, Gorgan, Iran. ${ }^{6}$ Social Determinants of Health Research Center, Research Institute for Health Development, Kurdistan University of Medical Sciences, Sanandaj 66179-13446, Iran. ${ }^{7}$ Department of Biostatistics, Faculty of Public Health, Iran University of Medical Sciences, Tehran, Iran

Received: 4 March 2021 Accepted: 16 June 2021

Published online: 10 July 2021

\section{References}

1. Pi-Sunyer FX. The medical risks of obesity. Obes Surg. 2002;12(1):S6-11.

2. Abúndez CO, Cázares GN, Cordero CJFR, Zetina DAD, Angona SR, de Voghel Gutiérrez S, et al. Encuesta nacional de salud y nutrición 2006. Instituto Nacional de Salud Pública. 2006.

3. Ramachandran A, Snehalatha C. Rising burden of obesity in Asia . J Obesity. 2010;2010:1-8.

4. Collaboration APCS. The burden of overweight and obesity in the AsiaPacific region. Obes Rev. 2007;8(3):191-6.

5. Hegde V, Dhurandhar N. Microbes and obesity —interrelationship between infection, adipose tissue and the immune system. Clin Microbiol Infect. 2013;19(4):314-20.

6. DiBaise JK, Zhang H, Crowell MD, Krajmalnik-Brown R, Decker GA, Rittmann BE, editors. Gut microbiota and its possible relationship with obesity. Mayo clinic proceedings; 2008: Elsevier.

7. Xu M-Y, Liu L, Yuan B-S, Yin J, Lu Q-B. Association of obesity with Helicobacter pylori infection: a retrospective study. World J Gastroenterol. 2017;23(15):2750.

8. Xu X, Li W, Qin L, Yang W, Yu G, Wei Q. Relationship between Helicobacter pylori infection and obesity in Chinese adults: a systematic review with meta-analysis. PLoS One. 2019;14(9):e0221076.

9. Hooi JK, Lai WY, Ng WK, Suen MM, Underwood FE, Tanyingoh D, et al. Global prevalence of Helicobacter pylori infection: systematic review and meta-analysis. Gastroenterology. 2017;153(2):420-9.

10. Kyriazanos ID, Sfiniadakis I, Gizaris V, Hountis P, Hatziveis K, Dafnopoulou A, et al. The incidence of Helicobacter pylori infection is not increased among obese young individuals in Greece. J Clin Gastroenterol. 2002;34(5):541-6.

11. Wu M-S, Lee W-J, Wang H-H, Huang S-P, Lin J-T. A case-control study of association of Helicobacter pylori infection with morbid obesity in Taiwan. Arch Intern Med. 2005:165(13):1552-5.

12. Arslan $\mathrm{E}$, Atılgan $\mathrm{H}$, Yavaşoğlu İ. The prevalence of Helicobacter pylori in obese subjects. Eur J Intern Med. 2009;20(7):695-7.

13. Kuipers E. Helicobacter pylori and the risk and management of associated diseases: gastritis, ulcer disease, atrophic gastritis and gastric cancer. Aliment Pharmacol Ther. 1997;11(S1):71-88.

14. Kim SS, Ruiz VE, Carroll JD, Moss SF. Helicobacter pylori in the pathogenesis of gastric cancer and gastric lymphoma. Cancer Lett. 2011;305(2):228-38
15. Smolka AJ, Backert S. How Helicobacter pylori infection controls gastric acid secretion. J Gastroenterol. 2012;47(6):609-18.

16. Den Hollander WJ, Broer L, Schurmann C, Meyre D, Den Hoed CM, Mayerle J, et al. Helicobacter pylori colonization and obesity-a Mendelian randomization study. Sci Rep. 2017;7(1):14467.

17. Zhang Y, Du T, Chen X, Yu X, Tu L, Zhang C. Association between Helicobacter pylori infection and overweight or obesity in a Chinese population. The Journal of Infection in Developing Countries. 2015;9(09):945-53.

18. Suki M, Leibovici Weissman Y, Boltin D, Itskoviz D, Tsadok Perets T, Comaneshter D, et al. Helicobacter pylori infection is positively associated with an increased BMI, irrespective of socioeconomic status and other confounders: a cohort study. Eur J Gastroenterol Hepatol. 2018;30(2):143-8.

19. Lender N, Talley N, Enck P, Haag S, Zipfel S, Morrison M, et al. associations between $\mathrm{H}$ elicobacter pylori and obesity-an ecological study. Aliment Pharmacol Ther. 2014;40(1):24-31.

20. Chen TP, Hung HF, Chen MK, Lai HH, Hsu WF, Huang KC, et al. Helicobacte pylori infection is positively associated with metabolic syndrome in Taiwanese adults: a cross-sectional study. Helicobacter. 2015;20(3):184-91.

21. Liu C-H, Chao W-T, Lin S-C, Lau H-Y, Wu H-H, Wang P-H. Malignant perivascular epithelioid cell tumor in the female genital tract: preferred reporting items for systematic reviews and meta-analyses. Medicine. 2019;98(2):e14072.

22. Moher D, Liberati A, Tetzlaff J, Altman DG. Preferred reporting items for systematic reviews and meta-analyses: the PRISMA statement. Ann Intern Med. 2009;151(4):264-9.

23. Moher D, Liberati A, Tetzlaff J, Altman DG, Group P. Preferred reporting items for systematic reviews and meta-analyses: the PRISMA statement. 2010.

24. Peterson J, Welch V, Losos M, Tugwell P. The Newcastle-Ottawa scale (NOS) for assessing the quality of nonrandomised studies in meta-analyses. Ottawa: Ottawa Hospital Research Institute; 2011.

25. Deeks J, Dinnes J, D'Amico R, Sowden A, Sakarovitch C, Song F, et al. Evaluating non-randomised intervention studies. Health Technol Assess. 2003;7(27):iii-x 1-173.

26. Al-Zubaidi AM, Alzobydi AH, Alsareii SA, Al-Shahrani A, Alzaman N, Kassim S. Body mass index and Helicobacter pylori among obese and non-obese patients in Najran, Saudi Arabia: a case-control study. Int J Environ Res Public Health. 2018;15(11):2586.

27. Cho I, Blaser MJ, François F, Mathew JP, Ye XY, Goldberg JD, et al. Helicobacter pylori and overweight status in the United States: data from the Third National Health and Nutrition Examination Survey. Am J Epidemiol. 2005;162(6):579-84

28. Ioannou G, Weiss N, Kearney D. Is Helicobacter pylori seropositivity related to body mass index in the United States? Aliment Pharmacol Ther. 2005;21(6):765-72.

29. Méndez-Sánchez N, Pichardo-Bahena R, Vásquez-Fernández F, LezamaMora Jl, León-Canales AL, Barredo-Prieto B, et al. Effect of Helicobacter pylori infection on gastric ghrelin expression and body weight. Rev Gastroenterol Mex. 2007;72(4):359-64.

30. Siddiqui B, Yakoob J, Abbas Z, Azmat R, Fatima SS, Awan S. Distribution of Helicobacter pylori infection and abnormal body-mass index (BMI) in a developing country. The Journal of Infection in Developing Countries. 2018;12(05):342-6.

31. Xu C, Yan M, Sun Y, Joo J, Wan X, Yu C, et al. Prevalence of Helicobacter pylori infection and its relation with body mass index in a Chinese population. Helicobacter. 2014;19(6):437-42.

32. Klok M, Jakobsdottir S, Drent M. The role of leptin and ghrelin in the regulation of food intake and body weight in humans: a review. Obes Rev. 2007:8(1):21-34.

33. Ahima RS, Flier JS. Leptin. Annu Rev Physiol. 2000;62(1):413-37.

34. Bado A, Levasseur S, Attoub S, Kermorgant S, Laigneau J-P, Bortoluzzi M-N, et al. The stomach is a source of leptin. Nature. 1998;394(6695):790.

35. Roper J, Francois F, Shue PL, Mourad MS, Pei Z, Olivares de Perez AZ, et al. Leptin and ghrelin in relation to Helicobacter pylori status in adult males. J Clin Endocrinol Metab. 2008:93(6):2350-7.

36. Osawa H, Nakazato M, Date Y, Kita H, Ohnishi H, Ueno H, et al. Impaired production of gastric ghrelin in chronic gastritis associated with Helicobacter pylori. J Clin Endocrinol Metab. 2005;90(1):10-6. 
37. Tschöp M, Weyer C, Tataranni PA, Devanarayan V, Ravussin E, Heiman ML. Circulating ghrelin levels are decreased in human obesity. Diabetes. 2001;50(4):707-9.

38. Nwokolo C, Freshwater D, O'hare P, Randeva H. Plasma ghrelin following cure of Helicobacter pylori. Gut. 2003;52(5):637-40.

39. Gunji T, Matsuhashi N, Sato H, Fujibayashi K, Okumura M, Sasabe $\mathrm{N}$, et al. Helicobacter pylori infection significantly increases insulin resistance in the asymptomatic Japanese population. Helicobacter. 2009:14(5):496-502

40. Marti A, Marcos A, Martinez JA. Obesity and immune function relationships. Obes Rev. 2001;2(2):131-40.

41. Krishnan EC, Trost $L$, Aarons S, Jewell WR. Study of function and maturation of monocytes in morbidly obese individuals. J Surg Res. 1982;33(2):89-97.
42. Palmblad J, Hallberg D, Engstedt L. Polymorphonuclear (PMN) function after small intestinal shunt operation for morbid obesity. Br J Haematol. 1980;44(1):101-8.

43. Moulin CM, Marguti I, Peron JPS, Rizzo LV, Halpern A. Impact of adiposity on immunological parameters. Arq Bras Endocrinol Metabol. 2009;53(2):183-9.

44. Xu X, Li W, Qin L, Yang W, Yu G, Wei Q. Relationship between Helicobacter pylori infection and obesity in Chinese adults: a systematic review with meta-analysis. PloS one. 2019;14(9):e0221076.

\section{Publisher's Note}

Springer Nature remains neutral with regard to jurisdictional claims in published maps and institutional affiliations.
Ready to submit your research? Choose BMC and benefit from:

- fast, convenient online submission

- thorough peer review by experienced researchers in your field

- rapid publication on acceptance

- support for research data, including large and complex data types

- gold Open Access which fosters wider collaboration and increased citations

- maximum visibility for your research: over $100 \mathrm{M}$ website views per year

At BMC, research is always in progress.

Learn more biomedcentral.com/submissions 